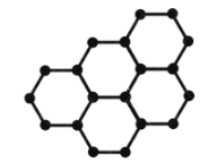

ICONSMAT

Institute of
Construction Materidis
Content list available at ICONSMAT

Journal of Construction Materials

Journal homepage: www.iconsmat.com.au/publication
Article history:

Received 2 December 2021

Received in revised form

6 December 2021

Accepted 30 December 2021

Available online 31 December 2021

\title{
Using blockchain technology to extend the vendor managed inventory for sustainability
}

\author{
Elham Ahmadi ${ }^{1}$, Roshaali Khaturia ${ }^{1}$, Pardis Sahraei ${ }^{1}$, Mohammad Niyayesh $^{2}$, Omid Fatahi \\ Valilai ${ }^{3 *}$
}

${ }^{1}$ M.Sc. student, Department of Mathematics \& Logistics, Jacobs University Bremen gGmbH, Bremen, Germany. ${ }^{2} \mathrm{PhD}$ candidate, Department of Mathematics \& Logistics, Jacobs University Bremen gGmbH, Bremen, Germany.

${ }^{3}$ Faculty member, Department of Mathematics \& Logistics, Jacobs University Bremen gGmbH, Bremen, Germany.

*Corresponding author: P: +49-421-200-3077; E: O.FatahiValilai@Jacobs-university.de

\begin{abstract}
Nowadays, Information Technology (IT) is changing the way traditional enterprise management concepts work. One of the most dominant IT achievements is the Blockchain Technology. This technology enables the distributed collaboration of stakeholders for their interactions while fulfilling the security and consensus rules among them. This paper has focused on the application of Blockchain technology to enhance one of traditional inventory management models. The Vendor Managed Inventory (VMI) has been considered one of the most efficient mechanisms for vendor inventory planning by the suppliers. While VMI has brought competitive advantages for many industries, however its centralized mechanism limits the collaboration of a pool of suppliers and vendors simultaneously. This paper has studied the recent research for VMI application in industries and also has investigated the applications of Blockchain technology for decentralized collaboration of stakeholders. Focusing on sustainability issue for total supply chain consisting suppliers and vendors, it has proposed a Blockchain based VMI conceptual model. The different capabilities of this model for enabling the collaboration of stakeholders while maintaining the competitive advantages and sustainability issues have been discussed.
\end{abstract}

DOI: 10.36756/JCM.v3.1.5 C2021 Institute of Construction Materials

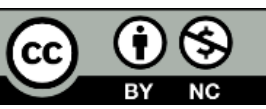

\section{Keywords}

Vendor Managed Inventory, Blockchain Technology, supply chain planning, sustainability. 


\section{Introduction}

management is one of the most important issues for production and manufacturing systems [1]. Due to enormous raw material and complicated interactions of vendors and suppliers, VMI has been proposed as one of the most effective solution to handle the inventory management system in recent decades [2]. However, this paradigm requires the continuous and seamless communication between vendors and suppliers [3, 4]. Moreover, the possibilities of the collaboration among suppliers and vendors in a collaborative environment can bring serious problems for $\mathrm{VMI}$ as the shared information among stakeholders can endanger the competitive advantages $[5,6]$. Also the complex interaction of supplies and vendors requires efficient tools to handle the financial transactions of stakeholders [7]. Considering the Blockchain technology, it seems the capabilities of this technology can enhance the VMI paradigm for complex and real time interaction of suppliers and vendors in globalized market [8, 9]. This paper has proposed a conceptual framework for enabling the collaboration of multi suppliers, multi vendors and has defined the capabilities of Blockchain technology to enhance the performance of a VMI system. The special focus will be on using smart contract, traceability, and consensus mechanism application for managing the relations of stakeholders in VMI system. Also, the paper has tried to enable the sustainability fulfilment to enable a sustainable VMI solution.

\section{Literature review}

\section{A. Sustainability}

The subject of sustainability has been a heated discussion in recent years, while the importance of profitability and environmental effects are considered mutually in businesses [10]. However, there has been a limited quantitative analysis for the planning of inventory in supply chains regarding to sustainability assessment [11].

VMI, which is categorized as a "push" inventory management, has introduced many advantages to both the supplier and vendor [12]. The main advantageous of VMI in downstream are considered as reducing inventory-related costs, increasing service levels, declining demand uncertainty, and reducing stockout. Synchronization of inventory and transportation decisions is another favourable consequence of VMI [12]. Reducing stock-outs will save costs for both supplier and buyer. It also provides more information on the demand patterns of customers for suppliers. Therefore, it enables suppliers to have better planning on the inventories [13].

VMI has been studied in some studies to determine its capability in sustainability [8]. Wee et al. proposed a model to consider VMI and life cycle cost and benefit analysis. Their model that was in response to Waste Electrical and Electronic Equipment (WEEE), Restriction of Hazardous Substance (RoHS) and Eco-Design Requirements for Energy-Using Products (EuP), presented that there are many factors affecting the green and sustainable product design, including selling price, depreciation, product return rate, remanufacturing, and inventory holding cost [14]. Irungu et al. considered VMI as a solution for achieving an efficient relationship between a supplier and a customer [12]. Malla and Prem mentioned that VMI contributes to reducing inventory costs by monitoring the inventory level of the customers [15]. In fact, in VMI, the supplier is responsible for controlling the buyer's inventory level, making replenishment decisions, and determining the timing. Therefore, VMI can have positive impacts on long- term sustainability by optimizing decisions in inventory holding costs, lead times, deteriorations, and customer satisfaction [16]. Gunasekaran et al. proposed VMI as one of the techniques that can be used in the production decision area of Sustainable Operation Management (SOM). According to their research, sustainability issues in the production area include remanufacturing, recycling, eco-friendly operations, sustainable order quantity, green products, and 
reverse logistics. Respectively, they proposed different OR models and techniques, such as closed queuing network models, production-inventory model, linear programming, inventory models, integrated production-inventory deteriorating model, and VMI system [17]. It is expected that inventory-related operations have significant consequences on economic, social, and environmental issues like carbon footprint [17]. Therefore, designing a platform for interactions between suppliers and vendors through the VMI system can enhance sustainability performance in terms of improving energy consumption, transportation costs, carbon footprint besides social parameters and profitability.

\section{B. Multiple Supplier Policy}

The Supply Chain Management (SCM) is the integration of multiple activities of different parties from downstream to the primary supplier. Information sharing among partners is one of the critical components of the supply chains. Therefore, suppliers and customers take advantage of ICTs to create a relationship to share knowledge and add value [18]. Some types of research studies propose IT-driven models for the processes of SCM. Nachiappan et al. presented an IT-driven normative model of VMI system and a knowledge management system (KMS) in a two-echelon supply chain for multiple suppliers and multiple buyers [19].

Research studies show that many papers are working on integrated inventory management in twoechelon supply chains with a single supplier and a single buyer [20,21]. While a limited amount of research works on this problem with a single supplier and multiple buyers [22], multiple- supplier and single or multiple-buyer situations have taken less attention in research works [23]. The pros and cons of a single-supplier and multi-supplier options in supply chains should be examined to explain this difference. High costs of product design and supplier development are the main reasons to hold a single supplier. By increasing the number of suppliers, more efforts for coordination and quality assurance are required. On the other hand, by having just one supplier, purchasing volumes increases. So, buyer has more power for negotiation in contracts such as obtaining quantity discounts, or payment terms [23]. However, a single supply has a significant dependency risk for the purchasing department. In contrast, competition for better price and quality among suppliers and higher flexibility toward risks is benefit of utilizing multiple-supplier systems [23]. Moreover, globalization and simplification in trade regulations provide an opportunity for businesses to move beyond the local supplies. Thus, dual or multiple sourcing appears attractive for many companies [24].

Table 1-The literature review for fulfilling the sustainability in VMNI

\begin{tabular}{|c|c|c|c|l|}
\hline $\begin{array}{c}\text { Research } \\
\text { studies }\end{array}$ & $\begin{array}{c}\text { Sustainable } \\
\text { VMI }\end{array}$ & $\begin{array}{c}\text { Multi-supplier } \\
\text { SCM }\end{array}$ & $\begin{array}{c}\text { Blockchain } \\
\text { technology }\end{array}$ & \multicolumn{1}{c|}{ Contribution } \\
\hline$[29]$ & $*$ & & $\begin{array}{l}\text { Providing a literature review on GrSCM with } \\
\text { classification on problem context in SCM, } \\
\text { methodologies and approach, and mathematical } \\
\text { models. }\end{array}$ \\
\hline$[17]$ & $*$ & $*$ & $\begin{array}{l}\text { Proposing SOM in system design (location } \\
\text { planning, capacity planning) and system operation } \\
\text { (Procurement, Production, Logistics). }\end{array}$ \\
\hline$[8]$ & $*$ & $*$ & $\begin{array}{l}\text { Proposing a new interaction mechanism between } \\
\text { retailers and vendors, which aims to improve } \\
\text { their supply chain strategy and inventory policies } \\
\text { based on a trustless and distributed mechanism. }\end{array}$ \\
\hline
\end{tabular}




\begin{tabular}{|c|c|c|c|c|}
\hline [25] & $*$ & & & $\begin{array}{l}\text { Proposing a new interaction framework based on } \\
\text { smart contracts and blockchain for governing the } \\
\text { relationship between the vendor and the buyer. }\end{array}$ \\
\hline [13] & $*$ & $*$ & $*$ & $\begin{array}{l}\text { This paper investigates the coordination of order } \\
\text { quantities amongst the players in a three-level } \\
\text { supply chain with a centralized decision process. } \\
\text { The first level of the supply chain consists of } \\
\text { multiple buyers, the second level of a vendor, and } \\
\text { the third level consists of multiple suppliers. }\end{array}$ \\
\hline [30] & $*$ & & & $\begin{array}{l}\text { Determining key factors for long-term } \\
\text { sustainability in VMI system by quantitative } \\
\text { approach such as descriptive statistics, } \\
\text { bootstrapping analysis, validity and reliability test, } \\
\text { and correlation analysis. }\end{array}$ \\
\hline [28] & $*$ & & & $\begin{array}{l}\text { This paper examines how blockchain is likely to } \\
\text { affect key SCM objectives such as cost, quality, } \\
\text { speed, dependability, risk reduction, sustainability } \\
\text { and flexibility. }\end{array}$ \\
\hline [10] & $*$ & & & $\begin{array}{l}\text { Discusses operations management capabilities } \\
\text { and the management of human resources to } \\
\text { achieve sustainability. }\end{array}$ \\
\hline [12] & $*$ & $*$ & & $\begin{array}{l}\text { Suggests adoption of VMI to build a strong } \\
\text { supplier-buyer relationship and increase } \\
\text { efficiency of operations in long-term. }\end{array}$ \\
\hline [14] & $*$ & & & $\begin{array}{l}\text { Considering VMI in reverse SCM and conducting } \\
\text { life cycle cost and benefit analysis. Mathematical } \\
\text { model demonstrates effects of selling price, } \\
\text { deteriorating rate, holding cost, product return } \\
\text { rate, and remanufactured quality on the model. }\end{array}$ \\
\hline [9] & $*$ & & & $\begin{array}{l}\text { The purpose of this paper is to combine the } \\
\text { blockchain technology and SCM in order to find a } \\
\text { feasible way to implement the VMI supply chain } \\
\text { mode. }\end{array}$ \\
\hline [31] & $*$ & & & $\begin{array}{l}\text { This paper considers a vendor-managed inventory } \\
\text { (VMI) supply chain consisting of a risk-averse } \\
\text { supplier and a risk-neutral retailer engaging in } \\
\text { sales promoting efforts. }\end{array}$ \\
\hline [15] & $*$ & & & $\begin{array}{l}\text { Presenting a case study to show the effectiveness } \\
\text { of VMI model is to cut inventory related costs and } \\
\text { keep inventory levels low by transferring the } \\
\text { responsibility of managing and replenishing } \\
\text { inventory to vendors. }\end{array}$ \\
\hline $\begin{array}{l}\text { This } \\
\text { paper }\end{array}$ & $*$ & $*$ & $*$ & $\begin{array}{l}\text { Providing a Blockchain based VMI model which } \\
\text { enables the sustainability objective through the } \\
\text { vendors and suppliers' collaboration }\end{array}$ \\
\hline
\end{tabular}




\section{Blockchain Technology}

VMI is an inventory management policy wherein the responsibility of replenishment of inventory is shifted from retailers to the suppliers [25]. It results into a two-way relationship that benefits both the suppliers and the retailers [26]. Implementation of $\mathrm{VMI}$ in supply chain has been seen to establish improved price strategies; improved retailer services; inventory reduction; measuring performance; and better environment performance [25]. In spite of having so many merits, it has been observed that not all VMI implementations are successful [25].

Blockchain technology is seen as a tool which can revolutionize and improve supply chain performance in numerous ways [25]. Blockchain technology is a diverse database that comprises of records and information of all digital events that have taken place, and these are then shared among the agents who are a part of blockchain [7]. It ameliorates traditional VMI system by establishing multiple features and configurations. These agreed upon terms are then abided by both the supplier and retailer [25].

Adoption of Blockchain in VMI assists in overcoming various shortcomings. It aids in reduction of cost (since the entire VMI system is now fully automated); increased order fulfillment (as the system is automated i.e., less human error) [25]; better traceability (as the other parties involved such as distributors etc. keep updating the status of the order using Blockchain technology); efficient storage management (no overflow of goods as the status of the inventory is updated) [27]; risk management; better sustainability [28]; auditability; security; and integrity.

\section{Proposed solution}

In this section, the conceptual framework for the collaboration among multiple suppliers and multiple customers in the VMI system is proposed. By taking advantage of blockchain technology, data from suppliers and customers are stored in relative solvers. These data include the number of orders from the side of customers and the number of supplies from suppliers. Each solver is responsible for the assignments of supplies to orders. Then, detailed information about allocations, fulfillments, backorders, ordering costs, inventory cost and holding cost should be transferred to the main dataset (main solver). According to the collected information, the main solver can be modified. The conceptual model of the proposed interactions is shown in Fig. 1.

\section{A. Framework Capabilities}

The proposed conceptual model describes the platform mechanisms for managing the contractual relations among customers and suppliers in the concept of VMI by implementing smart contracts and by taking advantage of blockchain technology. The necessity of utilizing blockchain technology includes traceability capability, smart contracts, and encrypted data. 


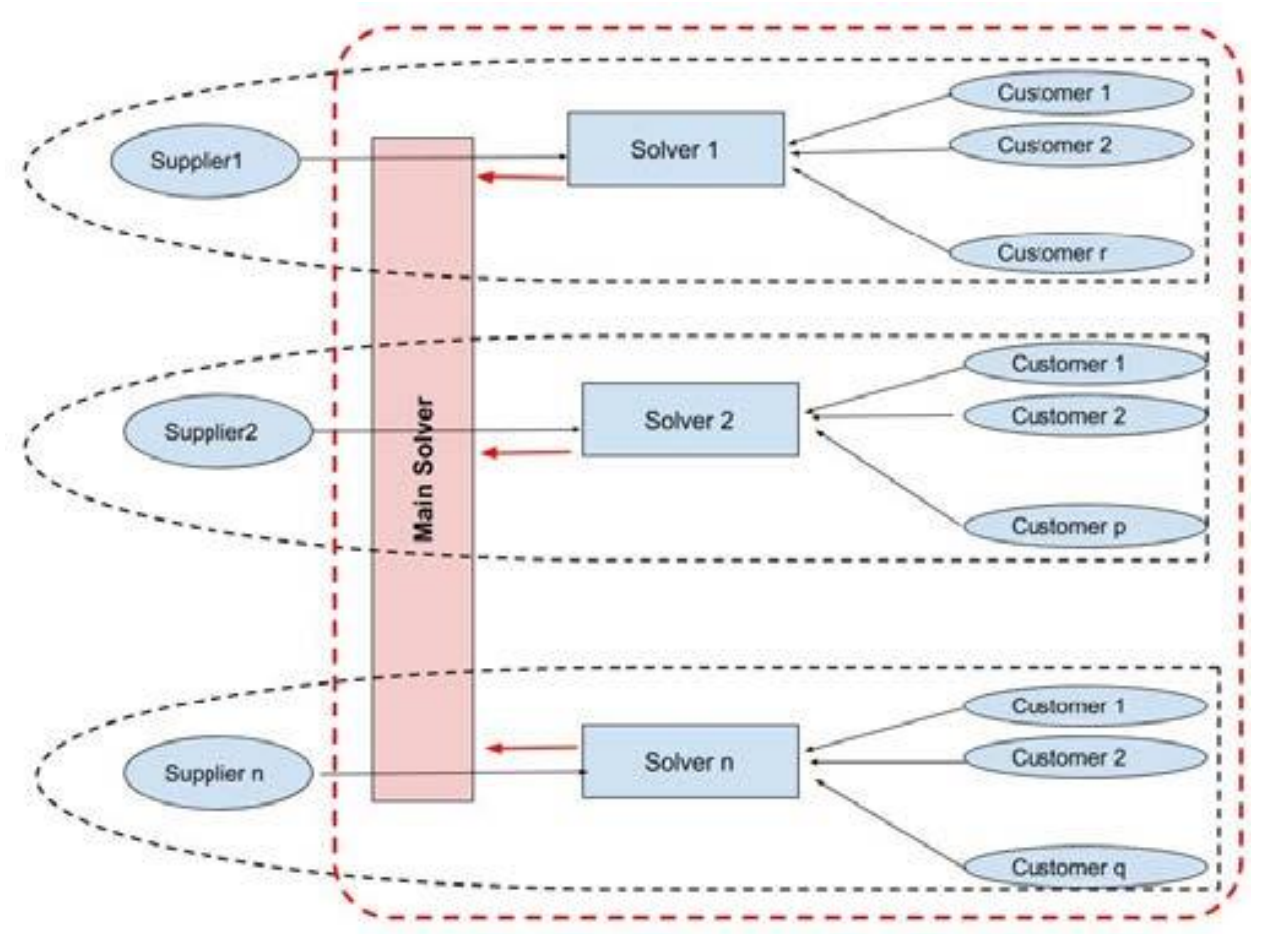

Figure 1-The conceptual model for enabling a VMI model for sustainability fulfillment while using blockchain technology

\section{Traceability}

Traceability is an extremely essential component of this process. Using blockchain technology, a framework will be formed which will enable us to trace the orders of all the suppliers individually i.e., for each supplier inventory holdings, back orders etc. could be traced separately along with tracing the assets right from the production till it reaches the end customer. This would in turn help in creating a decentralized immutable record of all the transactions [8]; ensuring proper allocation of all the assets especially for the ones with backorders; reducing wastage and increasing customer satisfaction.

\section{Smart Contract}

All transactions involve exchange of money. Smart contracts act as a safe medium which digitally facilitate exchange of money between the parties involved. The payment amount will be blocked by the solver till the transaction has been executed and then the payment will be done using smart contracts by the blockchain technology instead of having direct payment by the customers. Suppliers will not be able to track the information of other supplier's customers; hence this will ensure data security and provide a convenient and a secured platform for transactions.

\section{Encrypted Data}

Since the model involves VMI with multiple suppliers, it is imperative that suppliers do not take advantage of each other. Suppliers should have no knowledge about customer demands and inventory management of each other. Therefore, there is a need to ensure that the data are 
secured. For this, blockchain technology will be introduced. Utilizing the capabilities of Blockchain technology, no agents part of the blockchain will be able to read or interfere with any data stored. This would ensure that all the stakeholders involved in the process are able to maintain a safe, permanent, and tamper-proof digital record of transactions [27].

\section{B. Interaction of Agents inside the Proposed Model}

According to the proposed conceptual model, it is assumed that solvers are responsible for the initial allocation of orders. Therefore, each solver determines the number of fulfilled orders, and the number of backorders. In this model, it is assumed that all suppliers have specific types of customers and the main objective of individual solvers is to minimize the summation of ordering costs, inventory holding costs, and backorder costs. The result of the initial allocation of solvers is stored in the database. In the next step, the main solver will analyze the decisions made by all individual solvers. By calculating the total inventory costs and backorder costs of each supplier, the main solver makes further allocations between different customers and suppliers. In this way, the main solver can improve the performance of the VMI system.

\section{The Proposed Model's Capabilities}

This research develops a solution for the VMI system to include multi-suppliers by having smart contracts. By implementing the suggested platform, the inventory of all suppliers is managed simultaneously to reduce inventory holding costs and backorder costs. In this way, not only the customers receive their orders, but also the wastage rate of the unused inventory in the system will be decreased. Therefore, different suppliers and customers can sustainably work together in this system.

Based on the solution proposed by the research study, the VMI system will adopt multiple suppliers through blockchain technology. As discussed earlier, the lack of cooperation of several suppliers in the VMI system is a research gap, and it is considered the main objective of this research study. According to the conceptual model, we can develop the case in order to create structural relationships between different parties. In this case, each party has the role of supplier that should fulfill the specific demand orders of customers. By taking advantage of blockchain technology, the main solver can allocate excessive supplies of each party to the backorder of other parties. In this way, the main solver makes secure cooperation between multiple suppliers in the VMI system.

Indeed the capacity of the blockchain technology is not limited to the supply chain management systems and it can go beyond these boundaries. Multiple other studies specially the adoption of such technology in the construction industry are done that worthwhile reading [32-35].

\section{Conclusion}

This paper has developed the VMI system for the inventory management of multiple suppliers and multiple customers. According to the literature review, cooperation between several suppliers in the VMI system has not been discussed in previous research studies. Therefore, the conceptual structure and the mathematical model have been developed to create a relationship between multiple suppliers 
and customers through solvers by using the blockchain technology. The result of the model in the case of one VMI system with four different suppliers shows that by implementing this structure, total cost of inventory holding, and backorder costs will decrease in comparison to the case of having four different VMI systems with just one supplier. Therefore, by taking advantage of blockchain technology, we can create cooperation between different suppliers in the VMI system. So, not only the total inventory management cost decreases, but it also assures data

security and traceability in the system. However, this model is developed for homogenous customers to enable the system for exchanging demands between different parties. For further research studies, extending the model to heterogeneous customers is an innovative direction.

\section{References}

[1] J. Delaram and O. F. Valilai, "Development of a Novel Solution to Enable Integration and Interoperability for Cloud Manufacturing," in Procedia CIRP, 2016, vol. 52.

[2] S. H. R. Pasandideh, S. T. A. Niaki, and P. Ahmadi, "Vendor-managed inventory in the joint replenishment problem of a multi-product single- supplier multiple-retailer supply chain: A teacherlearner-based optimization algorithm," J. Model. Manag., vol. 13, no. 1, 2018.

[3] J. Delaram and O. Fatahi Valilai, "An architectural view to computer integrated manufacturing systems based on Axiomatic Design Theory," Comput. Ind., vol. 100, 2018.

[4] E. Aghamohammadzadeh, M. Malek, and O. F. Valilai, "A novel model for optimisation of logistics and manufacturing operation service composition in Cloud manufacturing system focusing on cloud- entropy," Int. J. Prod. Res., vol. 58, no. 7, pp. 1987-2015, Apr. 2020.

[5] G. Bodaghi, F. Jolai, and M. Rabbani, "Evaluating supply chain flexibility under demand uncertainty with smoothing approach and VMI considerations," J. Ind. Prod. Eng., vol. 35, no. 8, 2018.

[6] H. Mokhtari and M. T. Rezvan, "A single-supplier, multi-buyer, multi- product VMI productioninventory system under partial backordering," Oper. Res., vol. 20, no. 1, 2020.

[7] E. Aghamohammadzadeh and O. Fatahi Valilai, "A novel cloud manufacturing service composition platform enabled by Blockchain technology," Int. J. Prod. Res., vol. 58, no. 17, pp. 52805298, 2020.

[8] F. Casino, T. K. Dasaklis, and C. Patsakis, "Enhanced Vendor-managed Inventory through Blockchain," in 2019 4th South-East Europe Design Automation, Computer Engineering, Computer Networks and Social Media Conference (SEEDA-CECNSM), 2019, pp. 1-8.

[9] J. Wang, J. Liu, and L. Zheng, "Construction of VMI Mode Supply Chain Management System Based on Block Chain: 18th International Conference, ICA3PP 2018, Guangzhou, China, November 1517, 2018, Proceedings, Part IV," 2018, pp. 611-616.

[10] W. Adrian, H. Malcolm, and G. Paul, "The sustainability debate," Int. J. Oper. Prod. Manag., vol. 21, no. 12, pp. 1492-1502, Jan. 2001. 
[11] D. Spina, L. Di Serio, L. Brito, and A. L. Duarte, The influence of supply chain management practices in the enterprise performance. 2014.

[12] B. K. Irungu and K. Wanjau, "Effectiveness of vendor managed inventory systems in retail supermarkets in Kenya," Int. J. Bus. Public Manag., vol. 1, no. 1, pp. 194-205, 2011.

[13] M. Y. Jaber and S. K. Goyal, "Coordinating a three-level supply chain with multiple suppliers, a vendor and multiple buyers," Int. J. Prod. Econ., vol. 116, no. 1, pp. 95-103, 2008.

[14] H.-M. Wee, M.-C. Lee, J. C. P. Yu, and C. Edward Wang, "Optimal replenishment policy for a deteriorating green product: Life cycle costing analysis," Int. J. Prod. Econ., vol. 133, no. 2, pp. 603-611, 2011.

[15] R. Malla and V. Prem, "Vendor managed inventory model: a case study," J. Adv. Manag. Res., vol. 4, no. 1, pp. 83-88, Jan. 2007.

[16] T. T. Niranjan, S. M. Wagner, and S. M. Nguyen, "Prerequisites to vendor-managed inventory," Int. J. Prod. Res., vol. 50, no. 4, pp. 939-951, Feb. 2012.

[17] A. Gunasekaran, Z. Irani, and T. Papadopoulos, "Modelling and analysis of sustainable operations management: certain investigations for research and applications," J. Oper. Res. Soc., vol. 65, no. 6, pp. 806-823, Jun. 2014.

[18] V. Scuotto, F. Caputo, M. Villasalero, and M. Del Giudice, "A multiple buyer - supplier relationship in the context of SMEs' digital supply chain management," Prod. Plan. Control, vol. 28, no. 16, pp. 1378-1388, Dec. 2017.

[19] S. P. Nachiappan and N. Jawahar, "A genetic algorithm for optimal operating parameters of VMI system in a two-echelon supply chain," Eur. J. Oper. Res., vol. 182, no. 3, pp. 1433-1452, 2007.

[20] Y. Dong and K. Xu, "A supply chain model of vendor managed inventory," Transp. Res. Part E Logist. Transp. Rev., vol. 38, no. 2, pp. 75-95, 2002.

[21] C. C. Lee and W. H. J. Chu, "Who should control inventory in a supply chain?," Eur. J. Oper. Res., vol. 164, no. 1, pp. 158-172, 2005.

[22] M.-J. Yao and C.-C. Chiou, "On a replenishment coordination model in an integrated supply chain with one vendor and multiple buyers," Eur. J. Oper. Res., vol. 159, no. 2, pp. 406-419, 2004.

[23] S. Minner, "Multiple-supplier inventory models in supply chain management: A review," Int. J. Prod. Econ., vol. 81-82, pp. 265-279, 2003.

[24] H. Shin, D. A. Collier, and D. D. Wilson, "Supply management orientation and supplier/buyer performance," J. Oper. Manag., vol. 18, no. 3, pp. 317-333, 2000.

[25] T. Dasaklis and F. Casino, "Improving Vendor-managed Inventory Strategy Based on Internet of Things (IoT) Applications and Blockchain Technology," in 2019 IEEE International Conference on Blockchain and Cryptocurrency (ICBC), 2019, pp. 50-55.

[26] D. R. Kwame and K. S. Abekah, "Marketing and entrepreneurial success in emerging markets: the nexus," Asia Pacific J. Innov. Entrep., vol. 13, no. 2, pp. 168-187, Jan. 2019. 
[27] F. Casino, T. K. Dasaklis, and C. Patsakis, "A systematic literature review of blockchain-based applications: Current status, classification and open issues," Telemat. Informatics, vol. 36, pp. 55-81, 2019.

[28] N. Kshetri, "1 Blockchain's roles in meeting key supply chain management objectives," Int. J. Inf. Manage., vol. 39, pp. 80-89, 2018.

[29] S. K. Srivastava, "Green supply-chain management: A state-of-the-art literature review," Int. J. Manag. Rev., vol. 9, no. 1, pp. 53-80, Mar. 2007.

[30] C. S. Huoy, S. A. Rahim, N. A. A. Rahman, M. N. M. Nawi, and A. Ahmi, "Determination the key success factor for the success implementation and long-term sustainability of vendor managed inventory (VMI)," Int. J. Supply Chain Manag., vol. 7, no. 2, pp. 62-67, 2018.

[31] J. Liu, F. Huang, and C. Ma, "Coordination of VMI supply chain with replenishment tactic under risk aversion and sales effort," 4OR, 2020.

[32] F. Sartipi, "Dynamic data processing for building energy consumption," Journal of Construction Materials, vol. 2, no. 2021, pp. 2-4, 2020, doi: https://doi.org/10.36756/JCM.v2.2.4.

[33] F. Sartipi, "Influence of $5 \mathrm{G}$ and IoT in construction and demolition waste recycling-conceptual smart city design," Journal of Construction Materials, vol. 1, pp. 4-1, 2020, doi: https://doi.org/10.36756/JCM.v1.4.1.

[34] F. Sartipi, "Negative interest rate: Way to tackle inflationary housing prices," Journal of Construction Materials, vol. 2, pp. 4-1, 2021, doi: https://doi.org/10.36756/JCM.v2.4.1.

[35] F. Sartipi, "Publicizing construction firms by cryptocurrency," Journal of Construction Materials, vol. 2, pp. 3-1, 2021, doi: https://doi.org/10.36756/JCM.v2.3.1. 